\title{
Diagnostic yield of capsule endoscopy for small bowel arteriovenous malformations in patients with hereditary hemorrhagic telangiectasia: a systematic review and meta-analysis
}

\section{(c) (1) $(:)$}

\author{
Authors \\ Institutions \\ 1 Department of Internal Medicine, New York University \\ School of Medicine, Woodhull Medical and Mental \\ Health Center, Brooklyn, New York, United States \\ 2 Department of Hematology and Oncology, Lehigh Valley \\ Health Network, Allentown, Pennsylvania, United States \\ 3 Department of Gastroenterology and Hepatology, New \\ York University School of Medicine, Woodhull Medical \\ and Mental Health Center, Brooklyn, New York, United \\ States
}

Kevin Singh ${ }^{1}$, Ayla Zubair ${ }^{1}$, Andrew Prindle ${ }^{1}$, Ahmed Jamal Nadeem², Gulam Khan ${ }^{3}$

\section{ABSTRACT}

submitted 4.7.2018

accepted after submission 2.10.2018

\author{
Bibliography \\ DOI https://doi.org/10.1055/a-0799-9820 | \\ Endoscopy International Open 2019; 07: E282-E289 \\ (c) Georg Thieme Verlag KG Stuttgart · New York \\ ISSN 2364-3722
}

Corresponding author

Kevin Singh, MD, Department of Internal Medicine,

Woodhull Medical and Mental Health Center, 760

Broadway, Brooklyn, New York 11206

Fax: +1-718-963-8000

singh.kevin@gmail.com
Background and study aims Small bowel arteriovenous malformations (AVMs) pose a bleeding risk and have traditionally been diagnosed by invasive enteroscopic procedures in patients with hereditary hemorrhagic telangiectasia (HHT). Capsule endoscopy (CE) is emerging as a safe and non-invasive alternative for small intestinal evaluation, but its diagnostic yield and utility in diagnosing small bowel AVMs in HHT patients are understudied. The aim of this study was to meta-analyze the utility of CE for diagnosing AVMs in HHT patients.

Methods A meta-analysis and systematic review of the literature on CE in HHT patients identified in the PubMed, EMBASE, Scopus, and Cochrane databases from inception to March 2018 were conducted. Summary effects were estimated using a random effects model.

Results After applying exclusion criteria, five studies ( $\mathrm{n}=$ 124 patients) were eligible for meta-analysis. The pooled diagnostic yield for visualization of small bowel AVMs by CE was $77.0 \%$ (95\% Cl 65.8-85.4\%, $P<0.001)$.

Conclusions CE has a good diagnostic yield for small bowel AVMs in HHT. It can be regarded as a sufficient, noninvasive diagnostic modality for identifying small bowel AVMs in HHT patients.

\section{Introduction}

Hereditary hemorrhagic telangiectasia $(\mathrm{HHT})$, also known as Osler-Weber-Rendu syndrome, is a rare, autosomal-dominant syndrome characterized by multiple arteriovenous malformations (AVMs) in the mucous membranes, skin, liver, gastrointestinal tract (GIT), and brain [1]. The Curacao Criteria are often used to guide diagnosis of HHT based on the presence of key clinical features including spontaneous and recurrent epistaxis; multiple telangiectasias at characteristic sites such as the lips, oral cavity, fingers and nose; visceral lesions such as pulmonary, hepatic, cerebral, gastrointestinal, and spinal AVMs; or having a first-degree relative with HHT that meets diagnostic criteria. Patients who meet two criteria have a suspected diagnosis, while three or more criteria are diagnostic.

Small bowel bleeding has a number of causes, including erosions, ulcers, polyps, tumors, and vascular phenomena such as AVMs. GIT bleeding from small bowel AVMs is a common and important cause of mortality in HHT patients, and it is estimated that $33 \%$ of $\mathrm{HHT}$ patients will develop gastrointestinal bleeding during their lifetime [2]. Gastrointestinal bleeding is most commonly occult and detected as chronic iron deficiency anemia in patients with $\mathrm{HHT}$, but less frequently, AVMs can produce overt, massive gastrointestinal bleeding. Prior to 2001, 
the gold standard diagnostic and therapeutic interventions for small intestinal bleeding were invasive modalities such as push, intraoperative, or deep enteroscopy (spiral enteroscopy prior to 2001 and double and single balloon enteroscopy after 2001), due to their ability to visualize small bowel inaccessible to esophagogastroduodenoscopy or colonoscopy [3]. However, these modalities are not universally available, and not all endoscopists are trained to operate these enteroscopes. Furthermore, these procedures are considered invasive because patients require sedation, may require purgative bowel preparation, and the procedure itself can cause significant abdominal discomfort during and after the procedure. Capsule endoscopy (CE), a relatively noninvasive alternative for diagnosis of small intestinal gastrointestinal bleeding, involves ingesting a camera within a capsule that captures images as it traverses the gastrointestinal tract. CE is relatively inexpensive, requires less training for endoscopists, and may be more readily available than the invasive enteroscopic techniques. It is often considered noninvasive because it does not require conscious sedation and is generally well tolerated.

Because there are only approximately 5,000 to 8,000 patients with HHT worldwide [1], very few studies have examined the diagnostic value of CE for detecting small bowel AVMs in this population. To the best of our knowledge, this is the first meta-analysis of studies on the adequacy of CE for diagnosing small bowel AVMs in HHT patients. We also used this opportunity to review the therapeutic interventions that can be used in HHT patients when small bowel AVMs are identified.

\section{Methods}

The PubMed, EMBASE, Scopus, and Cochrane databases were searched from inception to March 26, 2018 according to PRISMA guidelines. Eligibility criteria were patients diagnosed with HHT who underwent CE to detect small bowel AVMs. Studies that involved children, pregnant women, and patients who did not undergo CE for evaluation of small bowel AVMs were excluded. The search criteria were "hereditary hemorrhagic telangiectasia" combined with "CE" or "arteriovenous malformations" within the titles and abstracts. Titles were then screened for exclusion criteria that would make the study ineligible, and articles were then independently selected and the abstracts and full texts reviewed by two authors (KS and AP). Any disagreements were resolved by discussion and, if a consensus had been lacking, the article would have been referred to another co-author (AN) for final adjudication. However, in this case, there were no disagreements. Bias assessment using the Cochrane tool for risk of bias assessment was also performed.

The number of patients who underwent CE and the number of subjects found to have AVMs by CE were extracted from each study. Using this information, the diagnostic yield or detection rate was calculated using the following formula: number of subjects found to have AVMs divided by the total number of subjects that underwent CE. To examine the diagnostic yield (with $95 \%$ confidence intervals [CI]) for CE detection of AVMs in HHT patients in each study, the interaction terms across studies were summarized by meta-analysis. Summary effects were estimated using a random effects model. The assumption of a constant interaction term across trials was tested for heterogeneity by examining $\mathrm{I}^{2}, \mathrm{~T}^{2}, \mathrm{Q}$, and $P$ values for heterogeneity. A sensitivity analysis was performed by including an additional meta-analysis using a fixed effects model. Analyses were performed in Comprehensive Meta-Analysis (CMA) version 3.2.

\section{Results}

\section{Study selection}

Of the 3,509 articles identified ( $\mathbf{F i g} \mathbf{1}$ ), none were in the Cochrane database. Six studies met the eligibility criteria and evaluated use of CE to identify AVMs in patients with HHT [4-9]. One study [9] was subsequently retracted by the author and/ or editor, leaving five studies for meta-analysis ( $>$ Fig. 1 and - Table 1).

\section{Detection rate of small bowel AVMs by CE}

In the five eligible studies, 124 patients were available for analysis ( Table 1) [4-8]. Overall, AVMs were detected by CE in $77.0 \%$ of patients $(95 \% \mathrm{Cl} 65.8-85.4 \%, P<0.001)$ with HHT using a random effects model ( $>$ Fig. 2a). In Ingrosso et al. [7], $50 \%$ of patients who underwent CE had suboptimal images, leading to inconsistency with the other studies and heterogeneity $\left(I^{2}=37.2, \mathrm{~T}^{2}=0.148, Q=6.34\right.$, and $\left.P=0.173\right)$. However, when this study was excluded, the pooled diagnostic yield of CE was $81.1 \%(95 \% \mathrm{Cl} 72.4-87.6 \%, P<0.001)$ and there was greater homogeneity $\left(I^{2}<0.0001, \mathrm{~T}^{2}<0.0001, \mathrm{Q}=1.09\right.$, and $P=$ 0.78 ) ( Fig. 2b). The calculated prediction interval was $77.0 \%$ (95\% Cl 66.5-87.6\%) when all five studies were included, while exclusion of the study by Ingrosso et al. reported a prediction interval of $81.1 \%(95 \% \mathrm{Cl} 66.8-95.4 \%)$. The overall results of our meta-analysis were similar in both fixed and random effects models, with the sensitivity analysis suggesting that the small sample size did not influence overall outcomes. A bias assessment was performed in accordance with the Cochrane tool for assessment of studies, and the risk of bias of these studies was consistently low despite the limitations that these studies were only prospective observational studies ( $>$ Table 2 ).

\section{Discussion}

AVMs are abnormal communications between the arteries and veins that bypass the normal capillary bed. The pathogenesis of AVMs in HHT is not completely understood, but histopathological examination of AVMs in these patients reveals an irregular endothelium, increased collagen and actin, and a convulsed basement membrane. At the molecular level, mutations that disrupt transforming growth factor $\beta$-mediated pathways impair angiogenesis and result in overall extreme blood vessel fragility [10]. The most frequent mutations affecting these pathways include mutations in the endoglin (ENG), activin receptor-like kinase 1 (ACVRL1 or ALK1), and SMAD4 genes and consequent deficiencies in their encoded proteins. ACVRL1 and ENG are essential components of cell surface receptors for transforming growth factor- $\beta$-mediated pathways, while SMAD4 


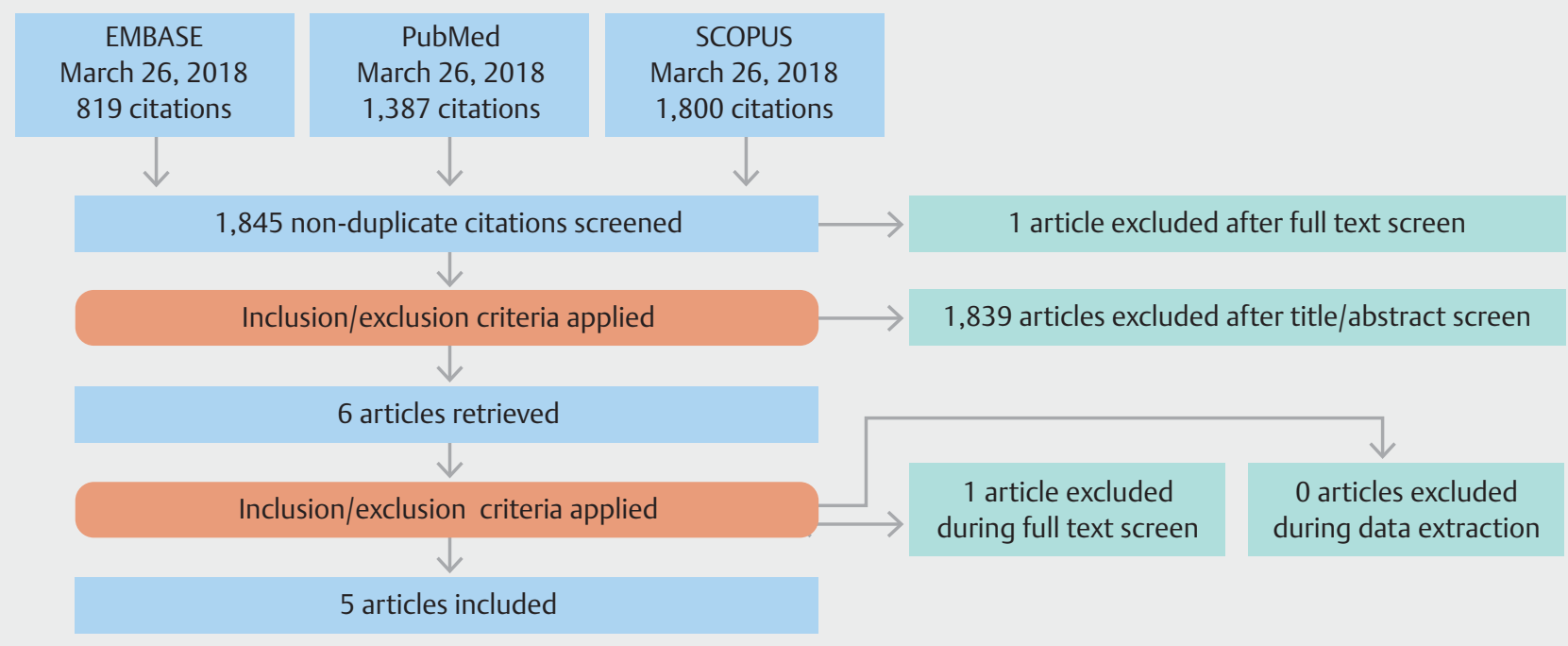

Fig. 1 Flowchart of study selection.

- Table 1 Studies included in the analysis.

\begin{tabular}{|c|c|c|c|c|c|c|c|c|c|c|}
\hline Study & Country & $\begin{array}{l}\text { Study } \\
\text { Design }\end{array}$ & $\begin{array}{l}\text { \# of sub- } \\
\text { jects } \\
\text { with } \\
\text { HHT en- } \\
\text { rolled }\end{array}$ & $\begin{array}{l}\text { Average } \\
\text { age } \\
\text { (years) }\end{array}$ & Gender & $\begin{array}{l}\text { \# of sub- } \\
\text { jects in- } \\
\text { cluded } \\
\text { in final } \\
\text { analysis }\end{array}$ & $\begin{array}{l}\text { Indication } \\
\text { of CE }\end{array}$ & $\begin{array}{l}\text { Average } \\
\text { small intes- } \\
\text { tinal transit } \\
\text { time (min- } \\
\text { utes) }\end{array}$ & $\begin{array}{l}\text { Excellent } \\
\text { adequacy } \\
\text { of CE visibi- } \\
\text { lity }\end{array}$ & $\begin{array}{l}\text { Location of } \\
\text { small bowel } \\
\text { AVMs }^{1}\end{array}$ \\
\hline $\begin{array}{l}\text { Ingrosso } \\
(2004)\end{array}$ & Italy & $\begin{array}{l}\text { Prospec- } \\
\text { tive }\end{array}$ & 20 & $54^{2}$ & $\begin{array}{l}11 \mathrm{M} \\
9 \mathrm{~F}\end{array}$ & $18^{3}$ & $\begin{array}{l}\text { Identifica- } \\
\text { tion of gas- } \\
\text { trointestinal } \\
\text { lesions }\end{array}$ & $274^{4}$ & NR & NR \\
\hline $\begin{array}{l}\text { Cham- } \\
\text { berlain } \\
(2006)\end{array}$ & USA & $\begin{array}{l}\text { Prospec- } \\
\text { tive }\end{array}$ & 38 & $54 \pm 13.2$ & $\begin{array}{l}18 \mathrm{M} \\
14 \mathrm{~F}\end{array}$ & $32^{5}$ & $\begin{array}{l}\text { Investiga- } \\
\text { tion of small } \\
\text { bowel } \\
\text { bleeding }\end{array}$ & NR & NR & $\begin{array}{l}\text { Proximal } \\
17(53 \%) \\
\text { Mid } \\
19(59 \%) \\
\text { Distal } 20(63 \%)\end{array}$ \\
\hline $\begin{array}{l}\text { Van Tuyl } \\
\text { (2006) }\end{array}$ & $\begin{array}{l}\text { Nether- } \\
\text { lands }\end{array}$ & $\begin{array}{l}\text { Prospec- } \\
\text { tive }\end{array}$ & 25 & $49 \pm 17$ & $\begin{array}{l}14 \mathrm{M} \\
11 \mathrm{~F}\end{array}$ & 25 & $\begin{array}{l}\text { Anemia } \\
\text { without a } \\
\text { source }\end{array}$ & $264 \pm 91$ & NR & $\begin{array}{l}\text { Ileum } 21(84 \%) \text {, } \\
\text { remainder of } \\
\text { the SB NR }\end{array}$ \\
\hline $\begin{array}{l}\text { Greve } \\
(2010)\end{array}$ & France & $\begin{array}{l}\text { Prospec- } \\
\text { tive }\end{array}$ & 30 & $57.7 \pm 11.2$ & $\begin{array}{l}10 \mathrm{M} \\
20 \mathrm{~F}\end{array}$ & $27^{6}$ & $\begin{array}{l}\text { Anemia } \\
\text { without a } \\
\text { source }\end{array}$ & $252^{4}$ & $50 \%$ & $\begin{array}{l}\text { Proximal } \\
27(100 \%) \\
\text { Distal } \\
15(55.6 \%)\end{array}$ \\
\hline $\begin{array}{l}\text { Canzio- } \\
\text { neri } \\
(2014)\end{array}$ & Italy & $\begin{array}{l}\text { Prospec- } \\
\text { tive }\end{array}$ & 22 & $59 \pm 9$ & $\begin{array}{l}13 \mathrm{M} \\
19 \mathrm{~F}\end{array}$ & 22 & $\begin{array}{l}\text { Identifica- } \\
\text { tion of gas- } \\
\text { trointestinal } \\
\text { lesions }\end{array}$ & $232^{4}$ & NR & $\begin{array}{l}\text { D:18 (81.8\%) } \\
\text { J: } 14(63.6 \%) \\
\text { I:13 (59\%) }\end{array}$ \\
\hline \multicolumn{11}{|c|}{$\begin{array}{l}\text { CE, capsule endoscopy; D, duodenum; F, female; J, jejunum; I, ileum; M, male; NR, not reported } \\
{ }^{1} \text { Definitions for location of small bowel AVMs: Chamberlain et al., areas of small bowel were divided into proximal, mid-, and distal regions according to thirds of time } \\
\text { of the capsule traversing the small bowel; Greve et al., areas of small bowel were divided into proximal and distal regions defined by halves of time of the capsule } \\
\text { traversing the small bowel; Canzioneri et al., areas of small bowel divided into accordingly by location duodenum (D), jejunum (J), and ileum (I) by thirds of time of the } \\
\text { capsule traversing the small bowel. } \\
{ }^{2} \text { Standard deviation not reported. } \\
{ }^{3} \text { Two subjects excluded from final analysis because of battery dysfunction of the capsule. } \\
{ }^{4} \text { Standard deviation not reported. } \\
{ }^{5} \text { Two subjects were excluded from final analysis because there was incomplete capsule transit to the cecum and four were excluded because the referred patients did } \\
\text { not have at least a possible diagnosis of HHT. }\end{array}$} \\
\hline
\end{tabular}




\section{Study name}

Canzonieri et al.

Greve et al.

Ingrosso et al.

van Tuyl et al.

Chamberlain et al.
Statistics for each study

Event Lower Upper

rate limit limit

$\begin{array}{lllll}0.773 & 0.557 & 0.902 & 2.408 & 0.016 \\ 0.867 & 0.682 & 0.952 & 3.308 & 0.001 \\ 0.556 & 0.331 & 0.760 & 0.474 & 0.635 \\ 0.840 & 0.643 & 0.939 & 3.040 & 0.002 \\ 0.780 & 0.606 & 0.891 & 2.966 & 0.003 \\ 0.770 & 0.658 & 0.854 & 4.283 & 0.000\end{array}$

a

\section{Study name}

Canzonieri et al.

Greve et al.

van Tuyl et al.

Chamberlain et al.

b
Statistics for each study

Event Lower Upper

rate limit limit

$\begin{array}{lll}0.773 & 0.557 & 0.902\end{array}$

$\begin{array}{lll}0.867 & 0.682 & 0.952\end{array}$

$\begin{array}{lll}0.780 & 0.606 & 0.891\end{array}$

0.811

0.876 $\begin{array}{lll}0.840 & 0.643 & 0.939\end{array}$

Z-Value P-Value

$\begin{array}{ll}2.408 & 0.016 \\ 3.308 & 0.001 \\ 3.040 & 0.002 \\ 2.966 & 0.003 \\ 5.804 & 0.000\end{array}$

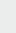

\section{Event rate and $95 \% \mathrm{Cl}$}

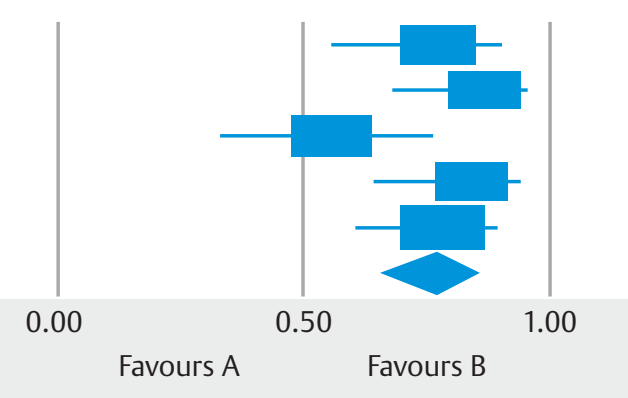

Event rate and $95 \% \mathrm{Cl}$

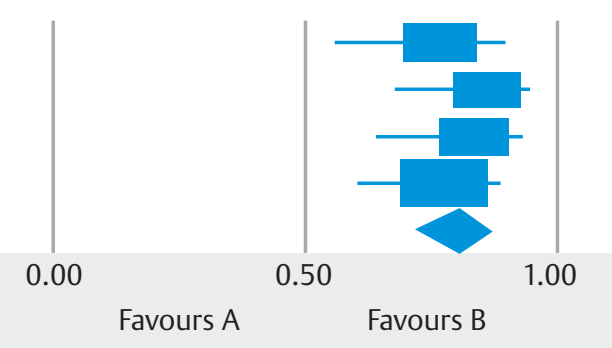

> Fig. 2 Forest plot demonstrating the pooled diagnostic yield for CE by meta-regression using a fixed effects model with inclusion of a all eligible studies and $\mathbf{b}$ after exclusion of the study by Ingrosso et al.

- Table 2 Bias assessment of included studies using the Cochrane tool for bias assessment.

\begin{tabular}{|c|c|c|c|c|}
\hline Author & Incomplete outcome data & Selective outcome reporting & Funding & Comments \\
\hline Ingrosso et al. & Low & Low & Unclear & \\
\hline Greve et al. & Low & Low & Low & \\
\hline Chamberlain et al. & High & Low & Low & $\begin{array}{l}7 \text { patients without HHT and } 2 \text { patients with } \\
\text { HHT were excluded because of incomplete } \\
\text { capsule transit time }\end{array}$ \\
\hline Canzioneri et al. & Low & Low & Low & \\
\hline Van Tuyl et al. & Low & Low & Low & \\
\hline Bias across studies & Low & Low & Low & \\
\hline \multicolumn{5}{|c|}{$\begin{array}{l}\text { A rating of "low," "high," and "unclear" risk of bias were given to each study. A designation of "low" was interpreted as plausible bias unlikely to seriously alter the } \\
\text { results, "high" was interpreted as plausible bias that seriously weakened the confidence in the results, and "unclear" was defined as plausible bias that raised some } \\
\text { doubt about the results. Other parameters including sequence generation, allocation concealment, and blinding of outcome accessors were not assessed because } \\
\text { the studies that were included were prospective observational studies. }\end{array}$} \\
\hline
\end{tabular}

acts as an intermediary between the extracellular growth factors and the nuclear transcriptional machinery [11-13].

Because GIT AVMs are found in the majority of patients with $\mathrm{HHT}$ and gastrointestinal bleeding is more prevalent in HHT patients older than 40 years, screening for iron deficiency anemia, a possible manifestation of gastrointestinal bleeding, is recommended through serial hemoglobin or hematocrit measurements and serum iron studies after age 35 [2,14-16]. Although significant epistaxis most frequently causes iron defi- ciency anemia in HHT patients, sources of bleeding from the GIT should be ruled out by endoscopy when epistaxis is absent or the degree of epistaxis is disproportionate to the degree of anemia. However, when gastrointestinal bleeding is suspected or evident, bleeding AVMs are most frequently found in the stomach or colon, so the recommended initial diagnostic assessment involves esophagogastroduodenoscopy (EGD) and colonoscopy. Prior to the introduction of CE, when a source of bleeding was not identified by EGD or colonoscopy, more inva- 
- Table 3 Reported diagnostic yields for different diagnostic techniques to diagnose causes of small intestinal bleeding[17]

\begin{tabular}{|l|l|}
\hline Diagnostic technique & Diagnostic yield \\
\hline Push enteroscopy & $15 \%-40 \%$ \\
\hline Single balloon enteroscopy & $41 \%-65 \%$ \\
\hline Double balloon enteroscopy & $40 \%-80 \%$ \\
\hline Spiral enteroscopy & $12 \%-59 \%$ \\
\hline Intraoperative enteroscopy & $58 \%-100 \%$ \\
\hline
\end{tabular}

sive diagnostic procedures such as push, deep, or intraoperative enteroscopy were used to rule out small bowel AVMs; however, the diagnostic yield was generally low with the exception of intraoperative enteroscopy, widely considered the most invasive modality because occasionally small bowel access may require an enterotomy site ( $\downarrow$ Table 3 ) [17]. These invasive diagnostic modalities have now largely been replaced with the less invasive $\mathrm{CE}$, even though the procedure is not therapeutic after lesion identification. Due to the rarity of $\mathrm{HHT}$, the sample sizes of relevant published studies are generally small, so here we sought to assess the combined effect sizes through meta-analysis in an effort to determine whether CE provides significant diagnostic yield to identify AVMs in HHT patients. We conclude that the diagnostic yield for AVMs by CE is sufficient to diagnose small bowel AVMs in these patients.

Our findings are important because CE can identify small bowel AVMs early and map the lesions in the GIT to identify patients who may benefit from therapeutic interventions that prevent the morbidity and mortality associated with GIT bleeding. Of the numerous available therapeutic interventions, AVMs tend to be amenable to endoscopic treatments, especially with single, proximal AVMs accessible to the enteroscope. Endoscopic treatments include standard electrocoagulation or neodymium yttrium-aluminum-Garnet lasers via push enteroscopy but, since the advent of deep enteroscopy, argon plasma coagulation has become the primary therapeutic choice [3]. Also, newer hemostatic powders (e.g., Hemospray, Endoclot, and Ankafred) primarily used to control bleeding at post-polypectomy sites, diverticula, and colonic tumors are now being investigated in prospective studies as a potential therapeutic option for GIT bleeding from AVMs [18] and may be useful in the HHT population.

In some instances, therapeutic control may be difficult to attain by endoscopy, such as when multiple attempts at endoscopic hemostasis (and consequent high risk of rebleeding) have been made. Also, surgery may be considered in patients: (1) with acute severe bleeding uncontrolled by multiple attempts at endoscopic hemostasis; and (2) who have had other treatments but continue to have recurrent chronic bleeding from a clearly identified source and have become transfusion dependent; however, surgery is considered a last-line option due to the postsurgical complications that may arise [19, 20]. There are also numerous non-endoscopic, pharmacological agents that can be used as adjunct therapies, either in combi- nation with endoscopic therapies or as monotherapy. These agents are especially useful in patients whose conditions remain refractory to or unsuitable for conventional therapies, such as those with multiple AVMs that would otherwise make endoscopic therapy challenging [4, 21]. These pharmacological options include estrogen - progesterone preparations, danazol, tamoxifen, thalidomide, lenalidomide, interferon- $2 \beta$, sirolimus, octreotide, aminocaproic acid or tranexamic acid, and bevacizumab ( $\triangleright$ Table 4) [22 - 24]. However, due to the rarity of HHT, significant reported adverse events (AEs) with these agents, and the poor evidence base from only case reports, case series, and small clinical trials $[1,25,26]$, a thorough discussion regarding the benefits and risks of initiating such therapies should be held between provider and patient and further studies are warranted.

Choosing a drug therapy for treatment of small bowel AVMs is difficult because of the weak evidence base [16]. The most recent HHT guidelines published in 2011 by the HHT Guidelines Working Group recommended hormonal therapies or antifibrinolytic agents such as aminocaproic or tranexamic acid in patients receiving medical therapy [14]. Hormonal therapies have been recommended to treat AVM lesions causing chronic gastrointestinal bleeding because HHT symptoms improved during pregnancy and worsened during menopause [27]. In patients started on antifibrinolytic agents, ruling out the presence of pulmonary AVMs is critical because these agents pose a risk of thrombosis. Of note, since the publication of these guidelines, reports on treatment of AVMs in the general population with hormonal therapies have provided mixed results, with some studies demonstrating a beneficial role in decreasing red blood cell transfusion requirements and overall rebleeding rates and others and a meta-analysis suggesting that these therapies ineffectively control bleeding $[28,29]$. Since the publication of these recommendations, bevacizumab, a drug extensively studied in HHT patients for treatment of epistaxis, has gained attention and is now among the most studied drugs in HHT patients with evidence of gastrointestinal bleeding in 16 case series/reports of 31 patients, four retrospective studies, and one Phase II study [30-44]. In these studies, bevacizumab decreased the frequency and severity of gastrointestinal bleeding and epistaxis, led to higher baseline hemoglobin levels, and reduced red blood cell transfusion requirements and dependency. Aside from treating GIT AVMs, bevacizumab also improved other HHT manifestations. such as multiple liver AVMs, normalized high cardiac output states, decreased biliary dilatation, resolved bilomas, normalized liver size, reduced celiac artery flow and arteriovenous shunting, lessened capsular pain and abdominal angina, and improved chronic liver disease to the point of allowing delisting of patients for liver transplantation [35].

Other frequently studied therapeutic agents include thalidomide and octreotide, both of which have demonstrated benefit in the general population to treat small bowel AVMs and, as a result, are recommended for use in the general population by the consensus opinion published by the Italian Society of Gastroenterology [29]. Octreotide reduces iron requirements and rebleeding events and improves rebleeding-free survival with- 
- Table4 Overview of potential pharmacological therapies for gastrointestinal AVMs currently under investigation [1, 25 - 26].

\begin{tabular}{|c|c|c|}
\hline Drug name & Mechanism of Action & Adverse effects \\
\hline Danazol & $\begin{array}{l}\text { Weak androgenic effects } \\
\text { and direct vascular stability }\end{array}$ & $\begin{array}{l}\text { Androgenic effects, hyperlipidemia, peliosis hepatis, hepatic adenoma, intracranial hyper- } \\
\text { tension, thromboembolic events }\end{array}$ \\
\hline $\begin{array}{l}\text { Estrogen-progester- } \\
\text { one combination }\end{array}$ & $\begin{array}{l}\text { Vascular stability, improved } \\
\text { coagulation, decreased } \\
\text { mesenteric blood flow }\end{array}$ & $\begin{array}{l}\text { Arterial and venous thromboembolism and thrombosis, hypertension, hyperlipidemia, } \\
\text { hepatic adenoma, headaches, angioedema }\end{array}$ \\
\hline Tamoxifen & Inhibition of angiogenesis & $\begin{array}{l}\text { Bone marrow suppression, hepatotoxicity, visual disturbances, thromboembolic events, } \\
\text { increased risk of uterine or endometrial cancers }\end{array}$ \\
\hline Bevacizumab & $\begin{array}{l}\text { Monoclonal antibody direc- } \\
\text { ted against vascular endo- } \\
\text { thelial growth factor } \mathrm{A}\end{array}$ & $\begin{array}{l}\text { Hypertension, heart failure, infusion reactions, arterial thromboembolism, posterior rever- } \\
\text { sible encephalopathy syndrome, gastrointestinal fistula or perforation, bleeding involving } \\
\text { the gastrointestinal tract, genitourinary tract, respiratory tract, and central nervous system }\end{array}$ \\
\hline Interferon-2 $\beta$ & Inhibition of angiogenesis & $\begin{array}{l}\text { Fever, chills, flu-like symptoms, hypothyroidism, immune-mediated hemolytic anemia, } \\
\text { connective tissue disorders }\end{array}$ \\
\hline Thalidomide & $\begin{array}{l}\text { Inhibitor of angiogenesis } \\
\text { through blockade of IL-6 } \\
\text { and other pathways }\end{array}$ & $\begin{array}{l}\text { Venous thromboembolism, Stevens-Johnson syndrome, dizziness, drowsiness, peripheral } \\
\text { neuropathy, seizures, constipation, abnormal liver function tests, bone marrow suppression, } \\
\text { increased risk of acute myeloid leukemia and myelodysplastic syndromes }\end{array}$ \\
\hline Lenalidomide & $\begin{array}{l}\text { Inhibitor of angiogenesis } \\
\text { through blockade of IL-6 } \\
\text { and other pathways }\end{array}$ & $\begin{array}{l}\text { Venous thromboembolism, Stevens-Johnson syndrome, constipation, abnormal liver func- } \\
\text { tion tests, bone marrow suppression, increased risk of acute myeloid leukemia and myelo- } \\
\text { dysplastic syndromes, and less neurotoxic presentations than thalidomide including dizzi- } \\
\text { ness, drowsiness, peripheral neuropathy }\end{array}$ \\
\hline Sirolimus & $\begin{array}{l}\text { Interleukin-2 inhibitor via } \\
\text { mTOR inhibition }\end{array}$ & $\begin{array}{l}\text { Peripheral edema, abdominal pain, constipation, diarrhea, nausea, acne, hypertension, } \\
\text { hyperlipidemia, and increased serum creatinine, and risk of infection, lymphoma, and } \\
\text { leukemia, }\end{array}$ \\
\hline Octreotide & $\begin{array}{l}\text { Decreased mesenteric } \\
\text { blood flow }\end{array}$ & Abnormal Schillings test, cholelithiasis, pancreatitis, hypothyroidism \\
\hline Tranexamic acid & Increased coagulation & $\begin{array}{l}\text { Central nervous system depression, hypersensitivity reactions, visual disturbances, seizures, } \\
\text { venous and arterial thrombosis or thromboembolism, ureteral obstruction }\end{array}$ \\
\hline Aminocaproic acid & Increased coagulation & $\begin{array}{l}\text { Intrarenal obstruction, myoglobinuria, renal failure, hyperkalemia, pulmonary embolism, } \\
\text { skeletal muscle weakness, leukopenia, thrombocytopenia, agranulocytosis, bradycardia, } \\
\text { arrhythmias, seizures, stroke, injection site necrosis, rashes, intracranial hypertension, } \\
\text { peripheral ischemia, syncope, myocardial thrombosis, delirium, headaches, }\end{array}$ \\
\hline
\end{tabular}

out significantly increasing AEs, so is considered a safe and effective option for rescue therapy in patients with actively bleeding angioectasias [29]. Thalidomide's benefits include stopping bleeding, reducing bleeding episodes within the first year of follow-up, and improving baseline hemoglobin levels, but hepatoxicity is not an uncommon $\mathrm{AE}$, with manifestations ranging from mild transaminase elevations to decompensated chronic liver disease with hepatic encephalopathy [29]. There has yet to be a comparison of thalidomide and its analogue lenalidomide for treating small bowel AVMs $[29,45]$. Use of tamoxifen, danazol, sirolimus, and IFN-2 $\beta$ is less well studied and they have only been described in case reports and may be reserved for patients with contraindications or who do not respond to other therapies [1, 16, 46-48].

Our study has some limitations. HHT is relatively rare, so only a limited number of studies have investigated use of CE in HHT patients with suspected small bowel AVMs and this was reflected through a broad prediction interval despite a large pooled effect size. Also, all of the available studies were small, prospective and observational and there are no randomized clinical trials. Based on our eligibility criteria, the study by Ingrosso et al. was included even though the CE views were frequently suboptimal, which is likely to have affected the overall diagnostic yield. Together, these factors may have contributed to effect size heterogeneity; indeed, exclusion of the Ingrosso et al. study increased homogeneity. Although exhaustive and concerted efforts were made, we did not find any unpublished studies, and our meta-analysis may have suffered from publication bias. Lastly, many of the enrolled patients did not have active gastrointestinal bleeding and because CE has the highest diagnostic yield during active bleeding, the diagnostic yield in these studies may have been underestimated.

\section{Conclusion}

In conclusion and despite its limitations, our meta-analysis revealed that $C E$ is a safe, noninvasive, and inexpensive diagnostic modality to diagnose and map AVMs along the GIT in patients with HHT. Although no studies compared the diagnostic yield of CE versus invasive enteroscopy to diagnose AVMs in this pop- 
ulation, our findings suggest that CE is a useful alternative to invasive enteroscopy for diagnosing AVMs in patients with HHT. Studies in the general population suggest that therapies started after CE increased hemoglobin levels and reduced risk of rebleeding, transfusion requirements, the number of gastrointestinal procedures performed, and the duration of hospitalization [49-55]. Hence, when AVMs are identified, endoscopic, surgical, and medical AVM therapies can be considered and decisions can be made according to the mapped locations of AVMs. Due to the heightened risk of gastrointestinal bleeding and mortality in HHT patients and current guidelines recommending against treating non-bleeding small bowel AVMs in asymptomatic patients in the general population, additional studies should focus on whether there is clinical benefit to early treatment of asymptomatic AVMs in HHT patients. If there is demonstrable benefit, CE may not only serve as an important diagnostic modality in HHT patients but may also become an important screening tool to prevent morbidity and mortality associated with GI bleeding [3, 56, 57].

\section{Competing interests}

None

References

[1] Garg N, Khunger M, Gupta A et al. Optimal management of hereditary hemorrhagic telangiectasia. J Blood Med 2014; 5: 191-206

[2] Kjeldsen AD, Kjeldsen J. Gastrointestinal bleeding in patients with hereditary hemorrhagic telangiectasia. Am J Gastroenterol 2000; 95 : $415-418$

[3] Gerson LB, Fidler JL, Cave DR et al. ACG Clinical Guideline: Diagnosis and Management of Small Bowel Bleeding. Am J Gastroenterol 2015; 110: $1265-1287$ quiz 1288

[4] Canzonieri C, Centenara L, Ornati F et al. Endoscopic evaluation of gastrointestinal tract in patients with hereditary hemorrhagic telangiectasia and correlation with their genotypes. Genet Med 2014; 16 : $3-10$

[5] Chamberlain SM, Patel J, Carter Balart J et al. Evaluation of patients with hereditary hemorrhagic telangiectasia with video capsule endoscopy: a single-center prospective study. Endoscopy 2007; 39: $516-520$

[6] Greve E, Moussata D, Gaudin JL et al. High diagnostic and clinical impact of small-bowel capsule endoscopy in patients with hereditary hemorrhagic telangiectasia with overt digestive bleeding and/or severe anemia. Gastrointest Endosc 2010; 71: 760 - 767

[7] Ingrosso M, Sabba C, Pisani A et al. Evidence of small-bowel involvement in hereditary hemorrhagic telangiectasia: a capsule-endoscopic study. Endoscopy 2004; 36: 1074-1079

[8] van Tuyl SA, Letteboer TG, Rogge-Wolf $C$ et al. Assessment of intestinal vascular malformations in patients with hereditary hemorrhagic teleangiectasia and anemia. Eur J Gastroenterol Hepatol 2007; 19: $153-158$

[9] Cianci R, Urgesi R, Tortora A et al. The role of capsule endoscopy and device assisted enteroscopy for small bowel lesions in hereditary hemorrhagic telangiectasia. Dig Liver Dis 2017; 25: pii: S1590-8658(17) 30891-5
[10] Westermann CJJ, Rosina AF, De Vries V et al. The prevalence and manifestations of hereditary hemorrhagic telangiectasia in the AfroCaribbean population of the Netherlands Antilles: A family screening. Am J Med Genet 2003; 116A: 324-328

[11] Govani FS, Shovlin CL. Hereditary haemorrhagic telangiectasia: a clinical and scientific review. Eur J Hum Genet 2009; 17: 860 - 871

[12] Johnson DW, Berg JN, Baldwin MA et al. Mutations in the activin receptor-like kinase 1 gene in hereditary haemorrhagic telangiectasia type 2. Nat Genet 1996; 13: 189-195

[13] McAllister KA, Grogg KM, Johnson DW et al. Endoglin, a TGF-beta binding protein of endothelial cells, is the gene for hereditary haemorrhagic telangiectasia type 1. Nat Genet 1994; 8: 345-351

[14] Faughnan ME, Palda VA, Garcia-Tsao G et al. International guidelines for the diagnosis and management of hereditary haemorrhagic telangiectasia. J Med Genet 2011; 48: $73-87$

[15] Plauchu H, de Chadarevian JP, Bideau A et al. Age-related clinical profile of hereditary hemorrhagic telangiectasia in an epidemiologically recruited population. Am J Med Genet 1989; 32: 291 - 297

[16] Longacre AV, Gross CP, Gallitelli M et al. Diagnosis and management of gastrointestinal bleeding in patients with hereditary hemorrhagic telangiectasia. Am J Gastroenterol 2003; 98: 59-65

[17] Committee AT, Chauhan SS, Manfredi MA et al. Enteroscopy. Gastrointest Endosc 2015; 82: 975 - 990

[18] Mourad FH, Leong RW. Role of hemostatic powders in the management of lower gastrointestinal bleeding: A review. J Gastroenterol Hepatol 2018; 2018: 1 -9

[19] Nardone G, Compare D, Martino A et al. Pharmacological treatment of gastrointestinal bleeding due to angiodysplasias: A position paper of the Italian Society of Gastroenterology (SIGE). Dig Liver Dis 2018; 50: $542-548$

[20] Sami SS, Al-Araji SA, Ragunath K. Review article: gastrointestinal angiodysplasia - pathogenesis, diagnosis and management. Aliment Pharmacol Ther 2014; 39: 15-34

[21] Gunjan D, Sharma V, Rana SS et al. Small bowel bleeding: a comprehensive review. Gastroenterol Rep (Oxf) 2014; 2: 262 - 275

[22] Gostout C], Bowyer BA, Ahlquist DA et al. Mucosal vascular malformations of the gastrointestinal tract: clinical observations and results of endoscopic neodymium: yttrium-aluminum-garnet laser therapy. Mayo Clin Proc 1988; 63: $993-1003$

[23] Sargeant IR, Loizou LA, Rampton D et al. Laser ablation of upper gastrointestinal vascular ectasias: long term results. Gut 1993; 34: $470-$ 475

[24] Bown SG, Swain CP, Storey DW et al. Endoscopic laser treatment of vascular anomalies of the upper gastrointestinal tract. Gut 1985; 26: $1338-1348$

[25] Szilagyi A, Ghali MP. Pharmacological therapy of vascular malformations of the gastrointestinal tract. Can J Gastroenterol 2006; 20: 171 178

[26] American Society of Health-System Pharmacists. ed. AHFS Clinical Drug Information. 2018: Available at: http://www.ahfsdruginformation.com/ Accessed November 14, 2018

[27] Koch HJ, Escher GC, Lewis JS. Hormonal management of hereditary hemorrhagic telangiectasia. J Am Med Assoc 1952; 149: 1376 - 1380

[28] Jackson CS, Gerson LB. Management of gastrointestinal angiodysplastic lesions (GIADs): a systematic review and meta-analysis. Am J Gastroenterol 2014; 109: 474-483

[29] Nardone G, Compare D, Martino A et al. Pharmacological treatment of gastrointestinal bleeding due to angiodysplasias: A position paper of the Italian Society of Gastroenterology (SIGE). Dig Liver Dis 2018; 50: $542-548$

[30] Epperla N, Hocking W. Blessing for the bleeder: bevacizumab in hereditary hemorrhagic telangiectasia. Clin Med Res 2015; 13: 32 - 35 
[31] Sehl ME, M Gruber T, McWilliams JP et al. Successful management of chronic gastrointestinal hemorrhage using bevacizumab in the setting of hereditary hemorrhagic telangiectasia. Am J Hematol 2015; 90: $561-563$

[32] Kochanowski J, Sobieszczańska M, Tubek $S$ et al. Successful therapy with bevacizumab in a case of hereditary hemorrhagic telangiectasia. Hum Vaccin Immunother 2015; 11: 680-681

[33] Bennesser AlaouiH, Lehraiki M, Hamaz S et al. Bevacizumab: a new success in hereditary hemorrhagic telangiectasia. Rev Med Internet 2015; 36: 623-625

[34] Wee JW, Jeon YW, Eun JY et al. Hereditary hemorrhagic telangiectasia treated with low dose intravenous bevacizumab. Blood Res 2014; 49: $192-195$

[35] Epperla N, Kapke JT, Karafin M et al. Effect of systemic bevacizumab in severe hereditary hemorrhagic telangiectasia associated with bleeding. Am J Hematol 2016; 91: E313-314

[36] Ou G, Galorport C, Enns R. Bevacizumab and gastrointestinal bleeding in hereditary hemorrhagic telangiectasia. World J Gastrointest Surg 2016; 8: $792-795$

[37] Bertoli LF, Lee PL, Lallone L et al. Intravenous bevacizumab therapy in a patient with hereditary hemorrhagic telangiectasia, ENG E137K, alcoholic cirrhosis, and portal hypertension. Case Rep Gastroenterol 2017; 11: $293-304$

[38] Guilhem A, Fargeton AE, Simon AC et al. Intravenous bevacizumab in hereditary hemorrhagic telangiectasia (HHT): A retrospective study of 46 patients. PLoS One 2017; 12: 1 - 12

[39] Bernardes C, Santos S, Loureiro R et al. Bevacizumab for refractory gastrointestinal bleeding in Rendu-Osler-Weber disease. GE Port J Gastroenterol 2018; 25: 91 - 95

[40] Al-Samkari H, Kritharis A, Rodriguez-Lopez JM et al. systemic bevacizumab for the treatment of chronic bleeding in hereditary hemorrhagic telangiectasia. J Intern Med 2018; 1: 1-19

[41] Iyer VN, Apala DR, Pannu BS et al. Intravenous bevacizumab for refractory hereditary hemorrhagic telangiectasia-related epistaxis and gastrointestinal bleeding. Mayo Clin Proc 2018; 93: 155-166

[42] Kanellopoulou T, Alexopoulou A. Bevacizumab in the treatment of hereditary hemorrhagic telangiectasia. Expert Opin Biol Ther 2013; 13: $1315-1323$

[43] Lupu A, Stefanescu C, Treton X et al. Bevacizumab as rescue treatment for severe recurrent gastrointestinal bleeding in hereditary hemorrhagic telangiectasia. J Clin Gastroenterol 2013; 47: 256-257

[44] Lazaraki G, Akriviadis E, Pilpilidis I et al. Low dose of bevacizumab is safe and effective in preventing bleeding episodes in hereditary hemorrhagic telangiectasia. Am J Gastroenterol 2011; 106: 2204-2206
[45] Bowcock S], Patrick HE. Lenalidomide to control gastrointestinal bleeding in hereditary haemorrhagic telangiectasia: potential implications for angiodysplasias? Br J Haematol 2009; 146: 220-222

[46] Haq AU, Glass J, Netchvolodoff CV et al. Hereditary hemorrhagic telangiectasia and danazol. Ann Intern Med 1988; 109: 171

[47] Massoud OI, Youssef WI, Mullen KD. Resolution of hereditary hemorrhagic telangiectasia and anemia with prolonged alpha-interferon therapy for chronic hepatitis C. J Clin Gastroenterol 2004; 38: 377 379

[48] Skaro AI, Marotta PJ, McAlister VC. Regression of cutaneous and gastrointestinal telangiectasia with sirolimus and aspirin in a patient with hereditary hemorrhagic telangiectasia. Ann Intern Med 2006; 144: $226-227$

[49] Park JJ, Cheon JH, Kim HM et al. Negative capsule endoscopy without subsequent enteroscopy does not predict lower long-term rebleeding rates in patients with obscure GI bleeding. Gastrointest Endosc 2010; 71: $990-997$

[50] Kim JB, Ye BD, Song Y et al. Frequency of rebleeding events in obscure gastrointestinal bleeding with negative capsule endoscopy. J Gastroenterol Hepatol 2013; 28: 834-840

[51] Pongprasobchai S, Chitsaeng S, Tanwandee T et al. Yield, etiologies and outcomes of capsule endoscopy in Thai patients with obscure gastrointestinal bleeding. World J Gastrointest Endosc 2013; 5: 122 127

[52] Min YW, Kim JS, Jeon SW et al. Long-term outcome of capsule endoscopy in obscure gastrointestinal bleeding: a nationwide analysis. Endoscopy 2014; 46: 59-65

[53] Saurin JC, Delvaux M, Vahedi K et al. Clinical impact of capsule endoscopy compared to push enteroscopy: 1-year follow-up study. Endoscopy 2005; 37: $318-323$

[54] Hindryckx P, Botelberge T, De Vos M et al. Clinical impact of capsule endoscopy on further strategy and long-term clinical outcome in patients with obscure bleeding. Gastrointest Endosc 2008; 68: 98-104

[55] Leighton JA, Sharma VK, Hentz JG et al. Capsule endoscopy versus push enteroscopy for evaluation of obscure gastrointestinal bleeding with 1-year outcomes. Dig Dis Sci 2006; 51: 891-899

[56] Strate LL, Gralnek IM. ACG Clinical Guideline: Management of patients with acute lower gastrointestinal bleeding. Am J Gastroenterol 2016; 111: 755

[57] Gralnek IM, Dumonceau JM, Kuipers EJ et al. Diagnosis and management of nonvariceal upper gastrointestinal hemorrhage: European Society of Gastrointestinal Endoscopy (ESGE) Guideline. Endoscopy 2015; 47: a 1-46 